\title{
Current trends in the digital transformation of higher education institutions in Russia
}

\author{
Alexey Mikheev, et al. [full author details at the end of the article]
}

Received: 29 October 2020 / Accepted: 9 February 2021/ Published online: 10 March 2021

(C) The Author(s), under exclusive licence to Springer Science+Business Media, LLC, part of Springer Nature 2021

\begin{abstract}
This research aimed to analyze the current trends in the digital transformation of educational institutions. The investigation lasted from November 2019 to May 2020 and was based on three higher educational institutions (HEIs) in the Russian Federation: Belgorod State University, Moscow State Institute of International Relations, and Kutafin Moscow State Law University. The number of respondents enrolled was 420 people. In an attempt to bring together views and experiences of different actors of the educational sector, three individual online surveys were conducted among administrative staff, teachers, and students of mentioned educational institutions. All respondents were provided with questionnaires aimed at identifying current trends in educational paradigm transformation and studying the extent to which digital strategies are applied in the process of HEIs' development. The detailed analysis of survey outcomes allowed indicating positive and negative trends in digitalization of educational processes from the perspective of university administrative staff, teachers, and students. Positive trends were: ensuring the availability of higher education through the implementation of full-fledged distance learning courses; enhancing the students' experience through the introduction of innovative teaching methods; providing open access to educational resources and research results; opportunity to participate in global "open science" initiatives; and reduction of higher education cost to ensure its accessibility and mass scale. The barriers to the digital transformation of the educational sphere were: lack of funds for the implementation of a comprehensive digital transformation strategy; resistance to changes on the part of the staff; and a low level of confidence in technological solutions used in teaching practice. As a result, the conducted investigation uncovered the essence of digital transformation in the institutional structures of the higher education sector. However, given that digitalization is a complex process affecting most spheres of socio-economic interaction, consideration of only positive and negative digital transformation trends is insufficient to thoroughly analyze global digital shifts and the formation of national vectors for digital society development.
\end{abstract}

Keywords Digital transformation · Digitalization · Higher education · Digital technologies - Social institutions 


\section{Introduction}

The digital era is defined by continuous streams of data containing information, knowledge, ideas and innovation. It is characterized by the rapid development of innovative technologies, where artificial intelligence, automation and digital platforms prevail. Deep penetration of global digitalization in all spheres of public life has changed not only the economic but also the social vision of the world (Okhrimenko et al. 2019).

Digital transformation is referred to as the global change of socio-economic relationships, characterized by the transfer of these relationships into the cyber-physical world. In turn, the concept of the cyber-physical world is based on the definition of the cyber-physical system - a set of devices, managed or controlled by computer algorithms, tightly integrated with the internet and its users. In cyber-physical systems, physical and program components are closely linked. Each of them may work in their own space and time scales, showing different complex behavior states and interacting with each other in different ways that change depending on the context (US National Science Foundation 2010). The process of technological transformation necessarily implies a change and coordination of a set of activities and interconnected subsystems (Strohmaier et al. 2019; Zinchenko et al. 2020).

At the present stage of social development, the effectiveness of the management of socio-economic processes in terms of a nation is determined by the level of implementation of the latest achievements in the digital field. The concepts of "digital technologies" and "digital economy" arose as a result of technological changes of the twentyfirst century and the integration of telecommunications, information and communication technologies, and innovations. Currently, digital technologies are transforming the relations between economic actors in the energy, construction, banking, transportation, retail, education, healthcare, media, and security sectors. In general, the digital economy is characterized by production flexibility, easy information access, zero marginal cost, and potentially serious consequences for the country's socio-economic development (Okhrimenko et al. 2019). Scientific literature defines digitalization as an integral component of the modern global economy, which contributes to the more rational use of resources (Antikainen et al. 2018), optimization of business management models (Rachinger et al. 2019), and implementation of structural changes (Heavin and Power 2018). Digitalization leads to the internationalization of industries and startups (Neubert 2018) and contributes to the creation of production ecosystems (Alcácer and CruzMachado 2019).

Digital transformation, with its many associated technologies, is arguably the most pervasive and rapid transformation that human society has seen, at least since the invention of the printing press. Nearly every aspect of socio-economic relationships is or was its subject. The pace of technology adoption is fast and unprecedented. Thus, the development of various innovative technological solutions, including artificial intelligence, the Internet of Things, quantum computing, machine-human interfaces, only intensify this continuing transformation. The effects of digitalization are felt at all levels, from individuals and communities to nation-states. One can be optimistic, pessimistic, or pragmatic about many of these changes, but they cannot be ignored (Gluckman and Allen 2018).

Digitalization is an integral part of global changes in the world economy, the effective functioning of which is possible only in an adequate digital ecosystem. The 
main criterion for the formation of a digital ecosystem is the maturity and stability of its institutional environment, including the totality of new institutions (Masyuk et al. 2020). The digitalization of all spheres of modern society has reached a level when qualitative changes are taking place in key categories that make up the basis of society (Sannikova and Kharitonova 2019).

The global digitalization has dramatically changed the expectations, needs and values of people who use mobile web, e-government and public services and platforms, make purchases in online stores, participate in startups and volunteer activities, work remotely, and are involved in the educational sphere (Mikheev et al. 2020).

Even though the technology itself is only a means to an end, technological developments lead to fundamental changes in higher education and society - and this at an unprecedented pace. Novel technological solutions remain exciting and aspiring as they come with untapped potential for exploring new problem-solving opportunities in teaching, learning and research (Jensen 2018).

Today, education is the basic need of every person, whereas digital education has become the modern trend, allowing one to be more focused on learning (Bilyalova et al. 2019). The possibility of creating and sharing knowledge increases every day. Thus, to attract new audiences, educational agents diversify their offer proposing distance courses and combining virtual learning with face-to-face training (Cunha et al. 2020). Recently, the transformation of training models using e-learning has been widely implemented in higher education as the use of digital technologies in education continues to be an effective solution for the active, independent, high quality, and sustainable learning process (Priatna et al. 2020). The introduction of e-learning is seen as an excellent way to provide independence in education and achieving one's personal learning goals (Kango and Ghozi 2019).

With the rapid introduction of digital technologies, the formation of digital skills has acquired paramount importance. Online and other technologies allow the effective acquisition of modern knowledge and skills necessary for an active social and economic life. The number of jobs requiring digital literacy and competence is rapidly increasing so that the ability to use these technologies in solving professional problems is becoming the main staffing requirement for personnel (Dorozhkin and Chernoskutova 2020; Latos et al. 2018). The creation of a favorable environment, the search for appropriate models of a public-private partnership with operators of nonformal digital education, and support for their regional development can contribute to the growth of private investment in this area. This will significantly expand the ability to acquire digital-related skills and professions. However, one of the important tasks for now is updating the state classifier of digital professions. Today's world needs to develop and approve a list of professions based on the current labor market requirements and digital trends followed by the creation of corresponding training programs in educational institutions (Okhrimenko et al. 2019).

Given that the transformation of society is inextricably linked with the transformation of the educational system, a need to study modern trends in educational practices in the context of digital transformations arises. This research aimed to identify positive and negative trends in the digital transformation of social institutions on the example of higher education. In order to achieve this goal, the following tasks were set:

- Determine the main vectors of digital transformation in the higher education sector; 
- Survey the administrative staff, teachers, and students of educational institutions to identify current trends in the transformation of the educational paradigm and investigate the degree of implementation of digital strategies for educational institutions' development;

- Distinguish the key challenges and opportunities of digital transformation in higher education;

- Define the major achievements of digital transformation at the institutional level.

\section{Materials and methods}

The integration between adaptive technology and learning skills has emerged in the effort to enhance educational outcomes through quality performance improvement. It has encompassed pedagogical, social and technological elements to offer some necessary benefits like a modern learning environment, flexibility, openness, and easy access to learning resources. In particular, the promotion of a range of pedagogical skills integrated with technological tools contributes to the development of such a learning environment that aligns student-teacher educational interaction better. Besides, the introduction of digital technologies into education provides an open and flexible transition from traditional pedagogy to innovative educational methodologies (Huda et al. 2018). The main ways of education digitalization are shown in Fig. 1.

Under the given context, it is critically important to bring together views and experiences of different actors of the educational process and discuss the values and principles that should underpin digital transformation from several perspectives. Consequently, this paper presents the results of studying the positive and negative trends in the digital transformation of educational processes in higher education from the point of view of administrative staff, university teachers, and students.

\subsection{Research design}

The present investigation lasted from November 2019 to May 2020 in three Russian higher educational institutions (HEIs): Belgorod State University, Moscow State Institute of International Relations, and Kutafin Moscow State Law University. It included three individual online surveys conducted among administrative staff (rectors, deans), teachers, and students. The number of respondents enrolled was 420 people, of which 43 people represented administrative staff, 137 people were teachers, and $240-$ students (Table 1).

All respondents were provided with questionnaires aimed at identifying current trends in the transformation of the educational paradigm and studying the extent to which digital strategies are applied in the HEIs' activities. Apart from this, the survey was also focused on identifying the main challenges and opportunities of digital transformation in higher education, namely:

- Extent to which the national regulatory framework for higher education is conducive to transition in the digital era;

- Quality of the internet infrastructure at the HEI;

- Significance of digital transformation for HEI's administrative staff; 


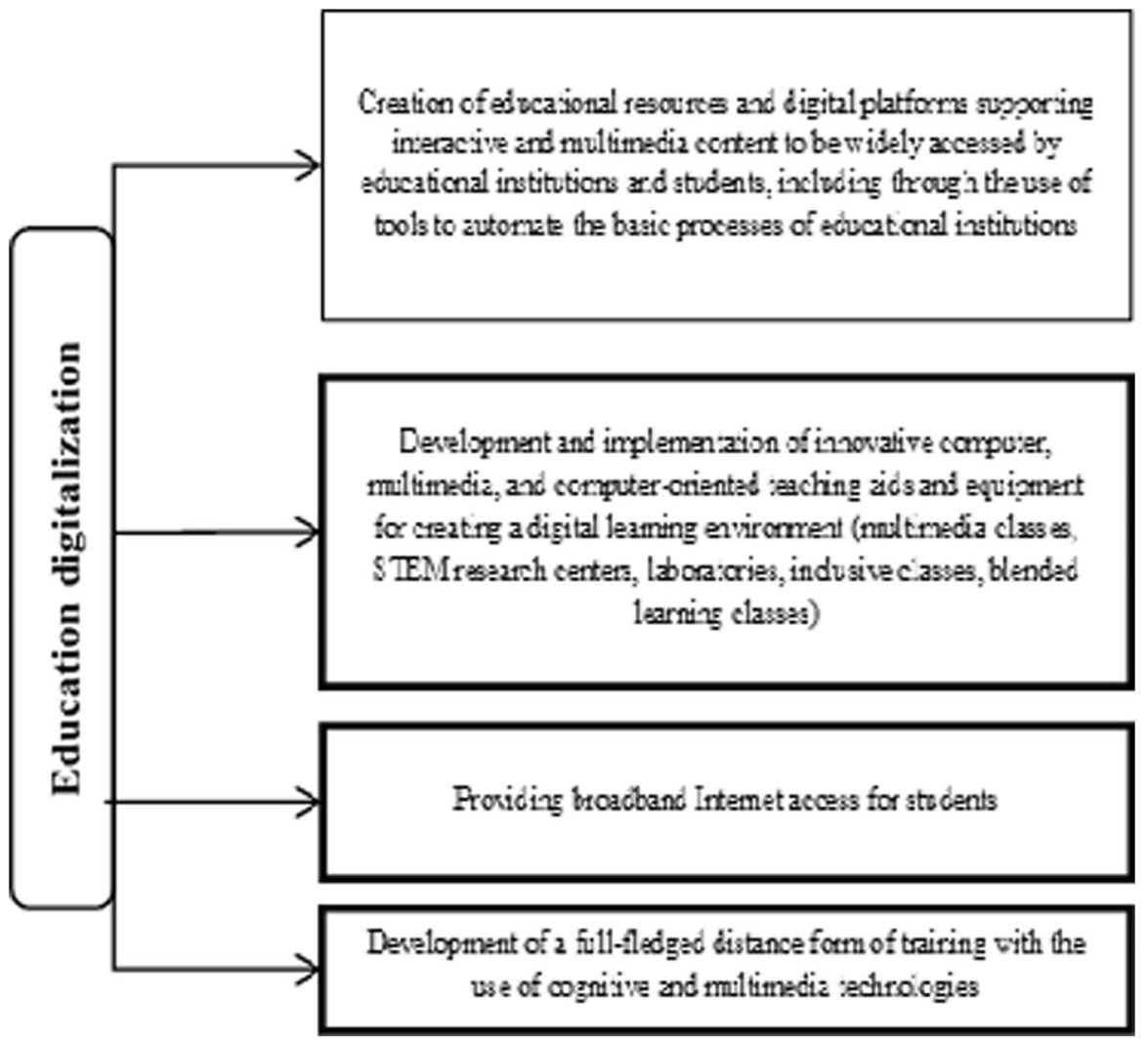

Fig. 1 Main ways to digitalize education. Developed by the authors based on data adapted from (Okhrimenko et al. 2019)

- Vectors for the implementation of digital solutions in the activities of the HEI;

- Availability of open educational practices aimed at acquiring new skills in interacting with digital technologies;

- Level of using the capabilities of learning management systems (LMS) at the HEI;

- Degree of confidentiality and adherence to ethical principles while managing student's data online;

- Level of integration of technological solutions in the educational process;

Table 1 Composition of the research sample

\begin{tabular}{lllll}
\hline University & Administrative staff & Teachers & Student & Total \\
\hline Belgorod State University & 11 & 51 & 84 & 146 \\
Moscow State Institute of International Relations & 17 & 39 & 79 & 135 \\
Kutafin Moscow State Law University & 15 & 47 & 77 & 139 \\
Total & 43 & 137 & 240 & 420 \\
\hline
\end{tabular}


- Degree of implementation of modern organizational training methods at the HEI (distance, hybrid and blended learning);

- Effort the HEI puts into ensuring the accessibility of educational content and research results;

- Extent to which the HEI supports lifelong learning;

- Key achievements in terms of using digital technologies;

- Central obstacles to digital transformation in the field of education and science;

- Difficulty of using digital technologies in education at the institutional level;

- Level of institutional readiness for implementing digitalization;

- Level of institutional openness for implementing digitalization;

- Level of institutional trust in new technological solutions implemented in education;

- Degree of digitalization impact on higher education;

- Role of higher education in the process of the digitalization of society.

The research participants were asked to fill out a questionnaire (Fig. 2) and choose one of the proposed answers, which, in their subjective opinion, reflects the true situation.

Research participants gave their consent to process and publish survey data.

\section{Results}

The survey results are presented in Table 2 .

From the perspective of HEIs' administrative staff, the national regulatory framework for higher education does conduce to transition in the digital era. This fact was confirmed by $63 \%$ of the surveyed. About $79 \%$ of respondents in this group consider digital transformation to be a priority. They also indicate that implementation of digital transformations proceeds in the mode of a complex interaction of administrative staff, teachers and students $(35 \%)$ and through the realization of the institutional strategic plan $(32 \%)$. For $63 \%$ of administrators, digital transformation is associated with radical changes in the approach to work and using new technologies (new governance procedures, curricula, teaching methods). The widespread use of LMS in HEIs was confirmed by $78 \%$ of administrators. On the other hand, the availability of opportunity for students to benefit from open educational practices to acquire new skills in interacting with digital technologies was reported only by $36 \%$ of administrative staff representatives. As many as $75 \%$ of university leaders indicated that technological solutions are fully integrated into the educational process of their HEIs. However, modern teaching methods are being implemented with varying success (a full-fledged distance learning $-46 \%$, hybrid and blended learning $-27 \%$, courses supported by online resources $-15 \%$, training in multimedia classrooms and STEM laboratories $12 \%$ ). The majority of administrators point out that their HEIs have complex programs for personnel training and retraining (79\%), and ensure confidentiality and ethics while managing students' data online $(81 \%)$. Besides, the prevailing part of educational institutions' leaders agrees that higher education plays a significant role in the digital transformation of society $(94 \%)$.

As for the surveyed teachers, $57 \%$ indicate that digital transformation does impact higher education and $46 \%$ note that the national higher education regulatory framework 
contributes to transition in the digital era. More than half of educators $(59 \%)$ confirmed that the quality of the internet infrastructure of their university needs improvement, while $74 \%$ believe that digital transformation is highly prioritized. When asked about how digital transformation translates into action, only $30 \%$ of enrolled university teachers indicated that the trend is toward a bottom-up approach with multiple initiatives taking place within the different faculties. For $48 \%$ of educators, digital

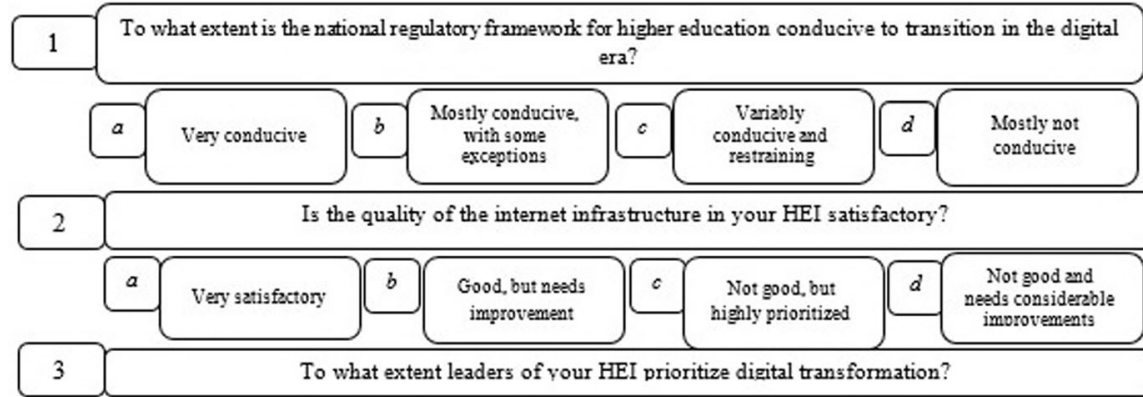

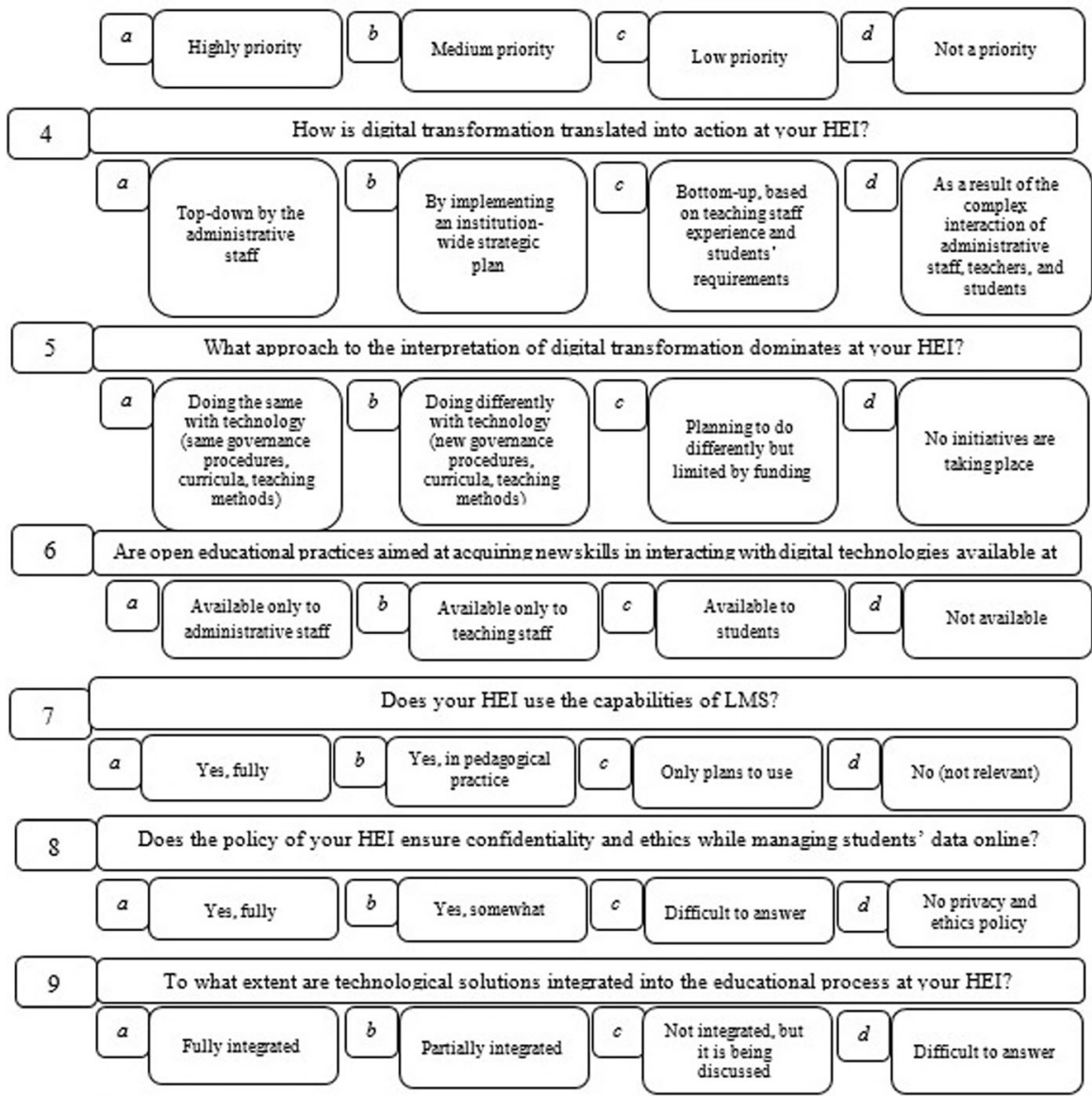

Fig. 2 Questionnaire data 


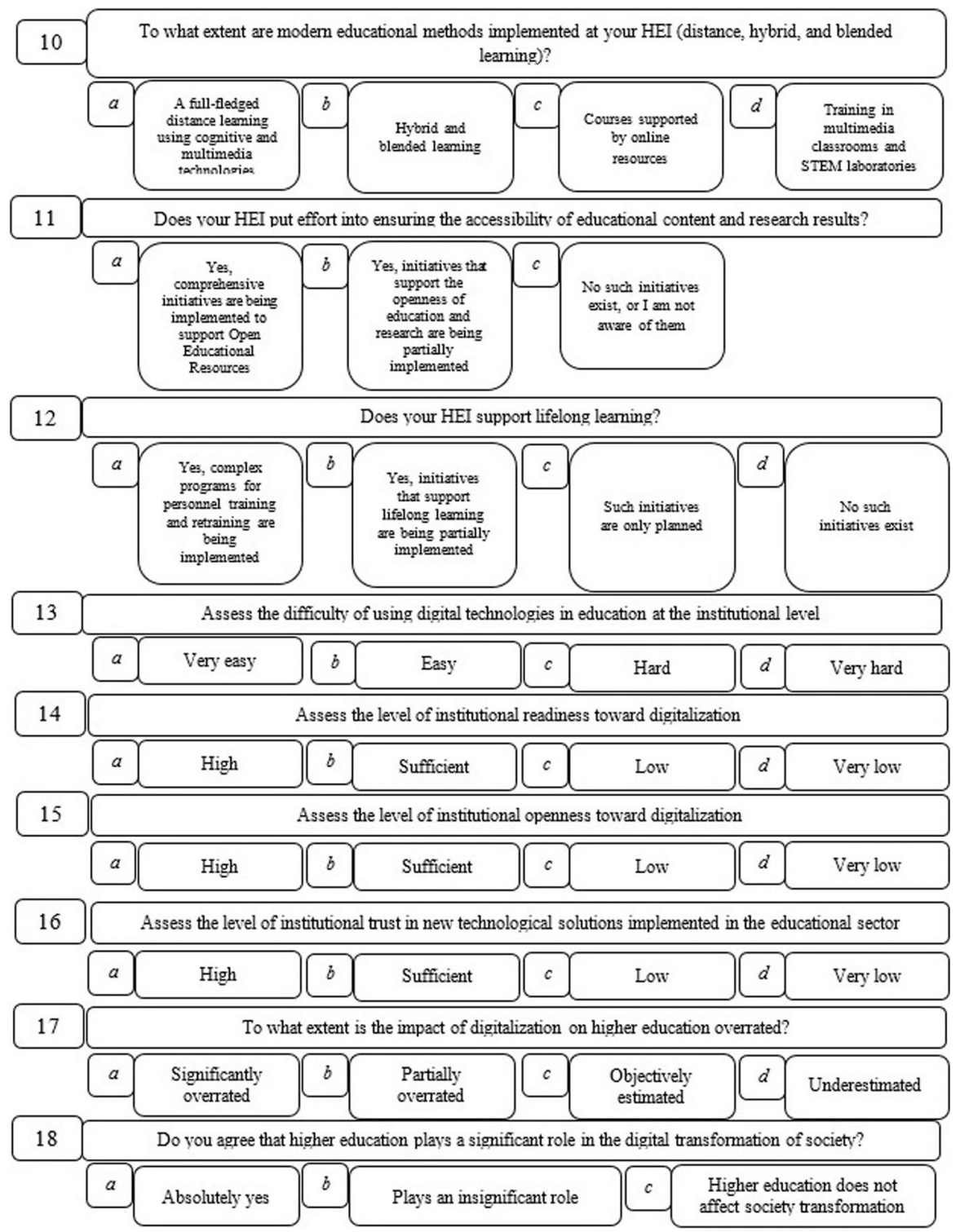

Fig. 2 (continued)

transformation is associated with doing the same with technology (the same governance procedures, curricula, teaching methods). The survey also revealed that among all university teachers enrolled, $51 \%$ consider that technological solutions are fully integrated into the educational process of their HEI. In the meantime, $69 \%$ already benefit from the use of LMSs and indicate that their HEIs put maximum efforts to ensure accessibility to educational content and research results. Using the potential of digital technologies in the education sector, educators associate with ease $(78 \%)$, readiness $(61 \%)$, openness $(60 \%)$ and trust in technological solutions (51\%). 
Table 2 Attitude toward education digitalization

Administrative Teachers Students staff

To what extent is the national regulatory framework for higher education conducive to transition in the digital era?

Very conducive

$63 \%$

$26 \%$

$46 \% \quad 57 \%$

Mostly conducive, with some exceptions

$7 \% \quad 13 \% \quad 14 \%$

Variably conducive and restraining

$4 \%$

$7 \% \quad 7 \%$

Is the quality of the internet infrastructure in your HEI satisfactory?

Very satisfactory

Good, but needs improvement

Not good, but highly prioritized

Not good and needs considerable improvements

To what extent leaders of your HEI prioritize digital transformation?

Highly priority

Medium priority

Low priority

Not a priority

How is digital transformation translated into action at your HEI?

Top-down by the administrative staff

By implementing an institution-wide strategic plan

Bottom-up, based on teaching staff experience and students' requirements

As a result of the complex interaction of administrative staff, teachers, $35 \%$

$16 \% \quad 18 \%$
and students

What approach to the interpretation of digital transformation dominates at your HEI? curricula, teaching methods)

Doing differently with technology (new governance procedures,

$30 \%$ curricula, teaching methods)

$\begin{array}{lll}63 \% & 29 \% & 73 \% \\ 6 \% & 16 \% & 12 \% \\ 1 \% & 7 \% & 3 \%\end{array}$

Planning to do differently but limited by funding

No initiatives are taking place

Are open educational practices aimed at acquiring new skills in interacting with digital technologies available at your HEI?

Available only to administrative staff

$\begin{array}{lll}12 \% & 29 \% & 49 \% \\ 51 \% & 47 \% & 31 \% \\ 36 \% & 21 \% & 17 \% \\ 1 \% & 3 \% & 3 \% \\ & & \\ 78 \% & 69 \% & 71 \% \\ 12 \% & 21 \% & 13 \% \\ 9 \% & 6 \% & 11 \% \\ 1 \% & 4 \% & 5 \%\end{array}$

Available only to teaching staff

Available to students

Not available

Does your HEI use the capabilities of LMS?

Yes, fully

Yes, in pedagogical practice

Only plans to use

$5 \%$ 
Table 2 (continued)

Administrative Teachers Students staff

Does the policy of your HEI ensure confidentiality and ethics while managing students' data online?

Yes, fully

$81 \% \quad 59 \% \quad 12 \%$

Yes, somewhat

$17 \% \quad 34 \% \quad 21 \%$

Difficult to answer

$1 \% \quad 6 \% \quad 56 \%$

No privacy and ethics policy

$1 \% \quad 1 \% \quad 11 \%$

To what extent are technological solutions integrated into the educational process at your HEI?

Fully integrated

$\begin{array}{lll}75 \% & 51 \% & 61 \% \\ 13 \% & 29 \% & 31 \% \\ 8 \% & 14 \% & 5 \% \\ 4 \% & 6 \% & 3 \%\end{array}$

Partially integrated

$4 \%$

Difficult to answer

To what extent are modern educational methods implemented at your HEI (distance, hybrid, and blended learning)?

A full-fledged distance learning using cognitive and multimedia tech- $46 \% \quad 36 \% \quad 45 \%$ nologies

Hybrid and blended learning

$27 \% \quad 36 \% \quad 31 \%$

Courses supported by online resources

$15 \% \quad 23 \% \quad 19 \%$

Training in multimedia classrooms and STEM laboratories

$12 \% \quad 5 \% \quad 5 \%$

Does your HEI put effort into ensuring the accessibility of educational content and research results?

Yes, comprehensive initiatives are being implemented to support Open $79 \% \quad 69 \%$ Educational Resources

Yes, initiatives that support the openness of education and research are $\quad 19 \% \quad 21 \% \quad 35 \%$ being partially implemented

No such initiatives exist, or I am not aware of them

Does your HEI support lifelong learning?

Yes, complex programs for personnel training and retraining are being $79 \%$ implemented

Yes, initiatives that support lifelong learning are being partially implemented

Such initiatives are only planned

$\begin{array}{lll}9 \% & 12 \% & 4 \% \\ 5 \% & 7 \% & 9 \%\end{array}$

No such initiatives exist

Assess the difficulty of using digital technologies in education at the institutional level
Very easy

$\begin{array}{llll}\text { Easy } & 19 \% & 12 \% & 5 \% \\ \text { Hard } & 9 \% & 7 \% & 3 \% \\ \text { Very hard } & 1 \% & 3 \% & 1 \% \\ \text { Assess the level of institutional readiness toward digitalization } & & & \\ \text { High } & 71 \% & 61 \% & 51 \% \\ \text { Sufficient } & 21 \% & 34 \% & 42 \% \\ \text { Low } & 7 \% & 4 \% & 6 \% \\ \text { Very low } & 1 \% & 1 \% & 1 \% \\ \text { Assess the level of institutional openness toward digitalization } & & & \\ \text { High } & 71 \% & 60 \% & 51 \% \\ \text { Sufficient } & 21 \% & 33 \% & 37 \%\end{array}$


Table 2 (continued)

\begin{tabular}{|c|c|c|c|}
\hline & $\begin{array}{l}\text { Administrative } \\
\text { staff }\end{array}$ & Teachers & Students \\
\hline Low & $5 \%$ & $6 \%$ & $10 \%$ \\
\hline Very low & $3 \%$ & $1 \%$ & $2 \%$ \\
\hline \multicolumn{4}{|c|}{ Assess the level of institutional trust in new technological solutions implemented in the educational sector } \\
\hline High & $61 \%$ & $51 \%$ & $73 \%$ \\
\hline Sufficient & $23 \%$ & $27 \%$ & $15 \%$ \\
\hline Low & $12 \%$ & $10 \%$ & $6 \%$ \\
\hline Very low & $4 \%$ & $2 \%$ & $6 \%$ \\
\hline \multicolumn{4}{|c|}{ To what extent is the impact of digitalization on higher education overrated? } \\
\hline Significantly overrated & $11 \%$ & $9 \%$ & $7 \%$ \\
\hline Partially overrated & $27 \%$ & $11 \%$ & $6 \%$ \\
\hline Objectively estimated & $41 \%$ & $57 \%$ & $42 \%$ \\
\hline Underestimated & $19 \%$ & $23 \%$ & $35 \%$ \\
\hline \multicolumn{4}{|c|}{ Do you agree that higher education plays a significant role in the digital transformation of society? } \\
\hline Absolutely yes & $94 \%$ & $91 \%$ & $75 \%$ \\
\hline Plays an insignificant role & $6 \%$ & $9 \%$ & $12 \%$ \\
\hline Higher education does not affect society transformation & $0 \%$ & $0 \%$ & $13 \%$ \\
\hline
\end{tabular}

As regards students, they find it very easy to use digital technologies during training (91\%). They show a high level of trust in technological solutions $(73 \%)$ and consider educational institutions quite open to the implementation of digital transformations (51\%). More than half of the surveyed students confirmed the priority of digitalization for their HEIs (54\%) and indicated that it is predominantly implemented according to the bottom-up approach (55\%). Simultaneously, $61 \%$ of respondents believe that technological solutions are fully integrated into their educational practice.

After the survey, study participants were also asked to name the key achievements and obstacles related to digital transformation in education. Based on their answers, positive and negative trends in the digital transformation of higher education were identified (Fig. 3).

\section{Discussion}

In today's world, there is a huge disruptive transition from the existing education system to an online education system based on modern digital technologies through websites, learning portals, video conferencing, YouTube, mobile applications and thousands of types of free websites for blended learning tools (Shahzad et al. 2020). Digital learning meets the needs of today's students based on their own needs and preferences, while being fruitful for a variety of reasons. First, the educational process can be carried out at any convenient time by purchasing subscriptions on different platforms or logging in to access the courses (Colchester et al. 2017). Second, it is possible to share and offer teaching materials in various digital formats such as 


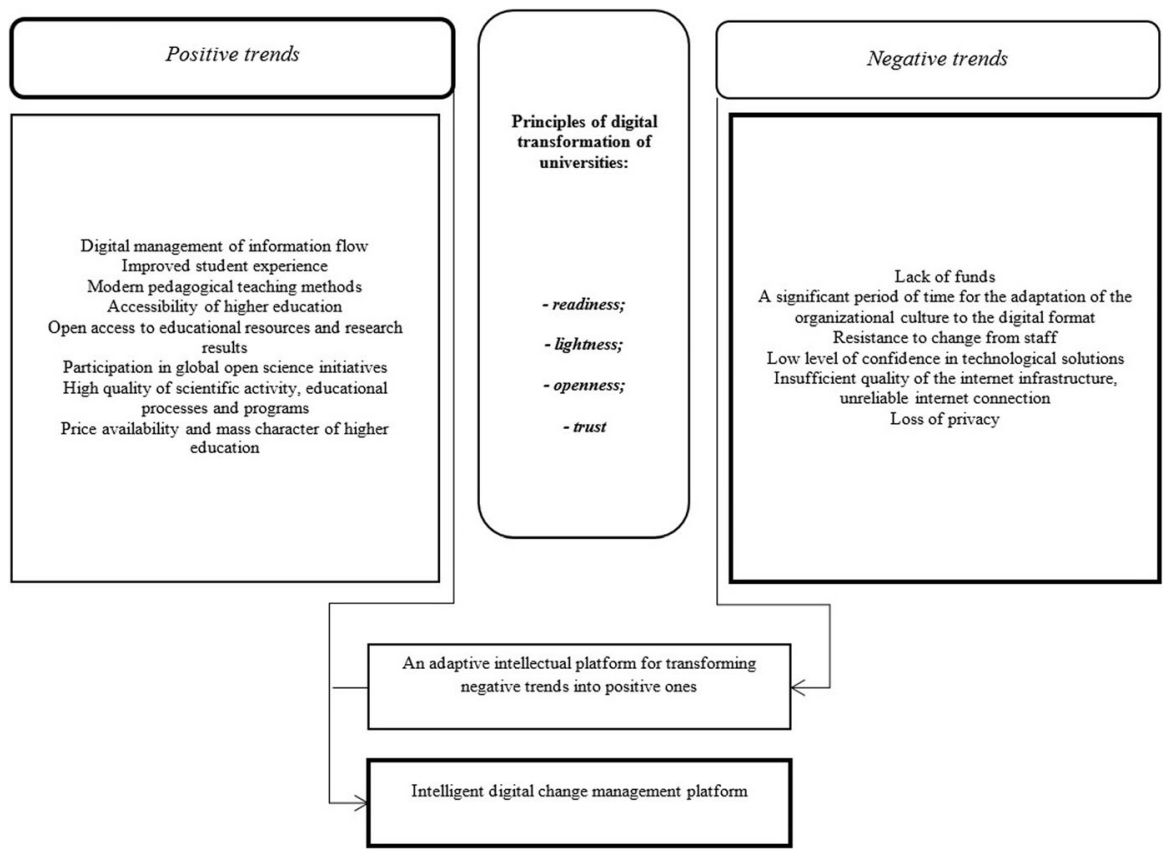

Fig. 3 Positive and negative trends in the digital transformation of educational institutions in the digital change management system

slideshows, audio, video, PDF files, emails, text documents, etc. Webinars and direct communication with teachers through various chat rooms, forums, or messaging are also an open opportunity to modernize and improve learning activities (Soni 2020). The success of digital education depends on such factors as good internet connectivity, learning software, digital skills, availability, and access to technology (Onyema et al. 2020). The digital educational format can make the learning process more innovative, flexible and student-centered as it takes place in a synchronous or asynchronous environment using various devices with internet access (Dhawan 2020).

The main problems with the transition to digital education include poor online learning skills among teachers, lack of appropriate support from technical teams, and the overload of traffic on online educational platforms. Not only teachers but also students face problems due to their incorrect attitude to learning and inability to selfdiscipline (Brazendale et al. 2017). There are numerous modern technologies available for online education, but sometimes they create many difficulties. These difficulties and challenges associated with modern technology include boot errors, installation problems, login problems, audio and video problems, etc. The challenge for educational institutions is not only to find new technologies and use them but and to rethink the educational process in a complex (Dhawan 2020). Online learning faces many concerns, ranging from student and teacher issues to content issues. The challenge for educational institutions is to attract students and increase their participation in the learning process. The challenge for teachers is to move from offline to online by changing their teaching methods. It is still difficult to develop content that not only covers the curriculum but also engages learners (Kebritchi et al. 2017). 
E-learning requires significant investments in purchasing and maintaining devices and equipment, training human resources, and developing online content. Therefore, an efficient and effective digital education system needs to be developed. Securing digital capital is critical since not all teachers and students have access to all digital devices, the internet, and Wi-Fi. Lack of proper digital tools, no internet connection, or an unreliable Wi-Fi connection can cause many problems resulting in lost learning opportunities. Institutions should make much more effort to ensure that every student and teacher has access to the digital resources they need (Dhawan 2020). While there are several challenges associated with e-learning, it has actually benefited learners and educators worldwide (Soni 2020).

\section{Conclusions}

The article examined the current trends in the digital transformation of higher education on the part of the university administrative staff, teachers, and students. Positive aspects for administrative staff manifested in improving information flow management, ensuring the availability of higher education through the implementation of full-fledged distance learning courses, and providing open access to educational resources and research results. The use of digital technologies is believed to reduce the cost of higher education, thereby ensuring its accessibility and mass scale. For teachers, the positive aspects of digital transformation were determined as the improvement of scientific activity through international interaction and cooperation in the virtual scientific space and the advancement of pedagogical teaching methods and quality of educational processes and programs. For students, the digital transformation benefits lie in improving their learning experience by introducing innovative teaching methods, expanding the possibilities of international interaction in the field of education and science, and opening up opportunities for participation in global "open science" initiatives. The obstacles to the digital transformation of the educational sphere of Russia are represented by insufficient financial resources for the implementation of a comprehensive digital transformation strategy; a long time to adapt the organizational culture to the digital format; resistance to changes on the part of the staff; lack of interest in progressive development and professional self-improvement; low level of confidence in technological solutions used in teaching practice; poor internet infrastructure quality, unreliable internet connection; and loss of confidentiality in the process of innovative development of educational methods.

The significance of this investigation stems from the fact that it allowed outlining the key principles for the effective digitalization of higher education at the institutional level, specifically: readiness, ease, openness, and trust.

\subsection{Research limitations}

This study brought an understanding of the essence of digital transformation in the institutional structures of the higher education sector. Considering that digitalization is a complex process that affects almost all spheres of socio-economic interaction, the examination of solely positive and negative trends of digital transformation in higher 
education is not enough to comprehensively analyze global digital shifts and the formation of national vectors for digital society development.

Code availability Not applicable.

Authors' contribution All authors contributed to the study conception and design. Material preparation, data collection and analysis were performed by Alexey Mikheev, Yana Serkina, Alexander Vasyaev. Alexey Mikheev and Yana Serkina wrote the first draft of the manuscript, while Alexander Vasyaev revised and edited the final version. All authors read and approved the final manuscript.Data availabilityData will be available on request.

\section{Declarations}

Conflict of interest The authors declare that they have no conflicts of interests.

\section{References}

Alcácer, V., \& Cruz-Machado, V. (2019). Scanning the industry 4.0: A literature review on technologies for manufacturing systems. Engineering Science and Technology, an International Journal, 22(3), 899-919.

Antikainen, M., Uusitalo, T., \& Kivikytö-Reponen, P. (2018). Digitalisation as an enabler of circular economy. Procedia CIRP, 73, 45-49.

Bilyalova, A. A., Salimova, D. A., \& Zelenina, T. I. (2019). Digital transformation in education. In International conference on integrated science (pp. 265-276). Cham: Springer.

Brazendale, K., Beets, M. W., Weaver, R. G., Pate, R. R., Turner-McGrievy, G. M., Kaczynski, A. T., \& Hippel, P. T. (2017). Understanding differences between summer vs. school obesogenic behaviors of children: The structured days hypothesis. International Journal of Behavioral Nutrition and Physical Activity, 14(1), 100.

Colchester, K., Hagras, H., Alghazzawi, D. M., \& Aldabbagh, G. (2017). A survey of artificial intelligence techniques employed for adaptive educational systems within E-learning platforms. Journal of Artificial Intelligence and Soft Computing Research, 7, 47-64.

Cunha, M. N., Chuchu, T., \& Maziriri, E. (2020). Threats, challenges, and opportunities for open universities and massive online open courses in the digital revolution. International Journal of Emerging Technologies in Learning (iJET), 15(12), 191-204.

Dhawan, S. (2020). Online learning: A panacea in the time of COVID-19 crisis. Journal of Educational Technology Systems, 49(1), 5-22.

Dorozhkin, E. M., \& Chernoskutova, I. A. (2020). The problems of formation of the National System of personnel training for vocational schools: Historical and genetic analysis. The Education and science journal, 22(3), 172-204.

Gluckman, S. P., \& Allen, K. (2018). Understanding wellbeing in the context of rapid digital and associated transformations. The International Network for Government Science Advice. https://www.ingsa.org/wpcontent/uploads/2018/10/INGSA-Digital-Wellbeing-Sept18.pdf. Accessed 10 October 2020.

Heavin, C., \& Power, D. J. (2018). Challenges for digital transformation-towards a conceptual decision support guide for managers. Journal of Decision Systems, 27(sup1), 38-45.

Huda, M., Maseleno, A., Teh, K. S. M., Don, A. G., Basiron, B., Jasmi, K. A., et al. (2018). Understanding Modern Learning Environment (MLE) in Big Data Era. International Journal of Emerging Technologies in Learning (iJET), 13(05), 71-85.

Jensen, T. (2018). Higher education in the digital era. The current state of transformation around the world in the digital era. Paris: International Association of Universities (IAU).

Kango, R., \& Ghozi, S. (2019). Tantangan Pembelajaran E-Learning di Perguruan Tinggi. SemanTECH (Seminar Nasional Teknologi, Sains dan Humaniora), 1(1), 137-144.

Kebritchi, M., Lipschuetz, A., \& Santiague, L. (2017). Issues and challenges for teaching successful online courses in higher education. Journal of Educational Technology Systems, 46(1), 4-29. 
Latos, B. A., Harlacher, M., Burgert, F., Nitsch, V., Przybysz, P., \& Mütze-Niewöhner, S. (2018). Complexity drivers in digitalized work systems: Implications for cooperative forms of work. Advances in Science, Technology and Engineering Systems Journal, 3(5), 171-185.

Masyuk, N., Bushueva, M., \& Bragina, Z. (2020). The institutional regulatory environment of the digital ecosystem: Theoretical approach and Russian experience. SHS Web of Conferences, 73, 01019.

Mikheev, A., Serkina, Y., \& Vasyaev, A. (2020). Digital transformation of social institutions. Talent Development \& Excellence, 12(2), 1-12.

Neubert, M. (2018). The impact of digitalization on the speed of internationalization of lean global startups. Technology Innovation Management Review, 8(5), 44-54.

Okhrimenko, I., Sovik, I., Pyankova, S., \& Lukyanova, A. (2019). Digital transformation of the socioeconomic system: Prospects for digitalization in society. Revista Espacios, 40(38), 26.

Onyema, E. M., Eucheria, N. C., Obafemi, F. A., Sen, S., Atonye, F. G., Sharma, A., \& Alsayed, A. O. (2020). Impact of coronavirus pandemic on education. Journal of Education and Practice, 11(13), 108-121.

Priatna, T., Maylawati, D., Sugilar, H., \& Ramdhani, M. (2020). Key success factors of e-learning implementation in higher education. International Journal of Emerging Technologies in Learning (iJET), 15(17), 101-114.

Rachinger, M., Rauter, R., Müller, C., Vorraber, W., \& Schirgi, E. (2019). Digitalization and its influence on business model innovation. Journal of Manufacturing Technology Management, 30(8), 1143-1160.

Sannikova, L. V., \& Kharitonova, Y. S. (2019). The trust and the digitalization of society. In In 2nd International Conference on Education Science and Social Development (ESSD 2019). Paris: Atlantis Press.

Shahzad, A., Hassan, R., Aremu, A. Y., Hussain, A., \& Lodhi, R. N. (2020). Effects of COVID-19 in Elearning on higher education institution students: The group comparison between male and female. Quality \& Quantity, 1, 1-22.

Soni, V. D. (2020). Global impact of E-learning during COVID 19. Available at SSRN, 3630073.

Strohmaier, R., Schuetz, M., \& Vannuccini, S. (2019). A systemic perspective on socioeconomic transformation in the digital age. Journal of Industrial and Business Economics, 46(3), 361-378.

US National Science Foundation (2010). Cyber-physical systems (CPS). https://www.nsf.gov/pubs/2010/ nsf10515/nsf10515.htm. Accessed 10 October 2020.

Zinchenko, Y. P., Dorozhkin, E. M., \& Zeer, E. F. (2020). Psychological and pedagogical bases for determining the future of vocational education: Vectors of development. The Education and science journal, 22(3), 11-35.

Publisher's note Springer Nature remains neutral with regard to jurisdictional claims in published maps and institutional affiliations.

\section{Affiliations}

\section{Alexey Mikheev ${ }^{1} \cdot$ Yana Serkina $^{2} \cdot$ Alexander Vasyaev $^{3}$}

\section{Alexey Mikheev}

mikheevalex87@rambler.ru; 7721177@gmail.com

1 Department of Public Administration, MGIMO University, Moscow, Russia

2 Department of Management and Marketing, Belgorod State National Research University, Belgorod, Russia

3 Department of Advocacy, Moscow State Law University named after O.E. Kutafin (MGLA), Moscow, Russian Federation 